\title{
Avaliação da qualidade da água em pisciculturas de Macapá, Amapá
}

A piscicultura é uma atividade de grande importância econômica, no entanto, o crescimento da atividade tem ocasionado impactos ambientais, com alterações aos ecossistemas aquáticos. O objetivo do presente estudo foi avaliar a qualidade da água e os impactos gerados pelos efluentes de piscicultura desenvolvida no município de Macapá, Amapá. Foram feitas análises da qualidade da água em dois viveiros, através do monitoramento mensal das variáveis físico-químicas e biológicas no período de janeiro a outubro de 2012. As variáveis analisadas foram oxigênio dissolvido, pH, condutividade elétrica, transparência, turbidez, cor aparente, sólidos totais dissolvidos, cloretos, dureza total, ferro total, temperatura da água, temperatura do ar e clorofila-a. Para a comparação das médias dos resultados das variáveis físico-químicas e biológica (clorofila-a) dos viveiros, aplicou-se o teste t de Student. Também se buscou compara os resultados do estudo com os limites determinados pelas Resoluções do CONAMA. Constatou-se diferenças entre as médias dos parâmetros oxigênio dissolvido, transparência, dureza total, cloretos, temperatura da água. Os valores de clorofila-a estiveram acima do limite determinado pelo CONAMA. Os resultados demonstram que os viveiros apresentaram uma alta carga de nutrientes, com elevação dos valores de clorofila-a, cor aparente, turbidez e diminuição da transparência. Constatou-se a influência do manejo e da sazonalidade sobre o comportamento dos parâmetros. A alta carga de nutrientes nos viveiros, traz uma preocupação em relação ao despejo dos efluentes e seus efeitos sobre os ambientes adjacentes.

Palavras-chave: Piscicultura; Qualidade; Água; Impacto Ambiental.

\section{Water quality assessment in Macapá, Amapá fisheries}

Fish farming is an activity of great economic importance, however, the growth of the activity causes environmental impacts, with changes in aquatic ecosystems The objective of the present study was to evaluate the water quality and the impacts generated by the effluents of fish farming developed in Macapá, Amapá. Two-year water quality analyzes were performed using monthly monitoring of physicochemical and biological variables from January to October 2012 . The variables analyzed were dissolved oxygen, $\mathrm{pH}$, electrical conductivity, transparency, turbidity, apparent color, total dissolved solids, chlorides, total hardness, total iron, water temperature, air temperature and chlorophyll. To compare the average of the results of the physicochemical and biological (chlorophyll-a) variables of the living, applied or student test. It also sought to compare the results of the study with the limits determined by CONAMA resolutions. Differences were found between the means of measurement of dissolved oxygen, transparency, total duration, chlorides, water temperature. Chlorophyll values - are above the limit determined by CONAMA. The results show that the nurseries presented a high nutrient load, with increased values of chlorophyll-a, apparent color, turbidity and decreased transparency. The influence of management and seasonality on the behavior of the parameters is verified. A high nutrient load in living beings raises concerns regarding the type of effluent and its effects on surrounding environments.

Keywords: Fish Farming; Water; Quality; Environmental Impact.

Topic: Uso de Recursos Naturais

Reviewed anonymously in the process of blind peer.
Received: 02/02/2020

Approved: 09/03/2020
Daniel da Silva Ladislau (D)

Universidade Estadual do Oeste do Paraná, Brasil http://lattes.cnpq.br/8098824072487689 http://orcid.org/0000-0002-0467-6353 daniel-ladislau@hotmail.com

Luís Roberto Takiyama (iD)

Instituto de Pesquisas Cientificas e Tecnológicas do Estado do Amapá, Brasil

http://lattes.cnpq.br/4281201198002253

http://orcid.org/0000-0001-9994-4666

luistakiyama@hotmail.com

Pauliana Leão de Souza

Universidade Estadual do Oeste do Paraná, Brasil http://lattes.cnpq.br/6911195798439428 http://orcid.org/0000-0003-1985-7322 paulianaleao@gmail.com
Maiko Willas Soares Ribeiro (it Universidade Nilton Lins, Brasil http://lattes.cnpq.br/6299874319353966 http://orcid.org/0000-0002-6155-5646 maikowillas@hotmail.com

Paulo Henrique Rocha Aride (iD Instituto Federal do Amazonas, Brasil http://lattes.cnpq.br/9087696929404160 http://orcid.org/0000-0001-9752-5003 aride@ifam.edu.br

Henrique David Lavander (iD) Instituto Federal do Espírito Santo, Brasil http://lattes.cnpq.br/5456683616099165 http://orcid.org/0000-0003-2102-3896 henrique.lavander@ifes.edu.br

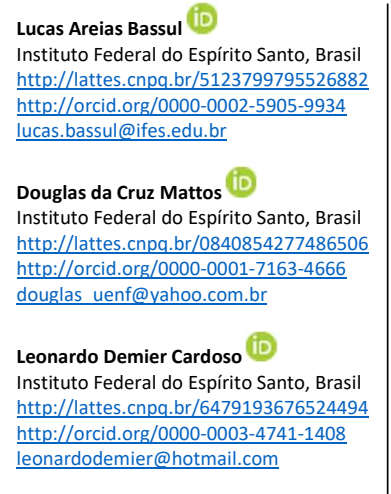

Adriano Teixeira de Oliveira (D) Instituto Federal do Amazonas, Brasil http://lattes.cnpq.br/9164471794674935 http://orcid.org/0000-0003-4988-9878 adriano.oliveira@ifam.edu.br

\section{Referencing this:}

LADISLAU, D. S.; TAKIYAMA, L. R.; SOUZA, P. L.; RIBEIRO, M. W. S.; ARIDE, P. H. R.; LAVANDER, H. D.; BASSUL, L. A.; MATTOS, D. C.; CARDOSO, L. D.; OLIVEIRA, A. T.. Avaliação da qualidade da água em pisciculturas de Macapá, Amapá. Revista Ibero Americana de Ciências Ambientais, v.11, n.2, p.402-417, 2020. DOI:

http://doi.org/10.6008/CBPC2179-6858.2020.002.0037 


\section{INTRODUÇÃO}

A aquicultura é uma atividade que tem tido um crescimento expressivo no cenário mundial nas últimas décadas, esse tem sido influenciado principalmente pelo declínio da pesca extrativista causada pela sobre-explotação dos estoques pesqueiros (FAO, 2016). No Brasil, o desenvolvimento da piscicultura tem apresentado um crescimento anual de aproximadamente 4,94\%, com a produção passando de 392.492 toneladas em 2013 para 507.122 toneladas em 2016 (IBGE, 2017).

No cenário nacional da piscicultura, a região Norte contribuiu com cerca de $29,5 \%$ o que representa uma produção de 149.745 toneladas, na qual o estado de Rondônia foi o maior produtor nacional com 90.636 toneladas gerando cerca de $\mathrm{R} \$ 624.039,00$ para o país (IBGE, 2017). A piscicultura nesta região tem crescido em razão do crescimento da demanda de pescado e devido as condições propiciais ao desenvolvimento de uma produção continua, o que tem tornando a piscicultura uma das atividades econômicas locais mais importantes (ANJOS et al., 2015).

A expansão piscícola, tem trazido preocupações aos órgãos gestores em relação ao uso dos corpos hídricos, pois, os lançamentos de efluentes das propriedades muitas vezes são ricos em nutrientes, o que acabam causando alterações ecológicas aos ecossistemas aquáticos, prejuízos aos empreendimentos vizinhos e ao meio ambiente (MACEDO et al., 2010). Entre os principais problemas oriundos da piscicultura estão a eutrofização dos ambientes aquáticos, o aumento de resíduos sólidos ou dissolvidos, alterações dos parâmetros físico-químico da água e mortalidade dos peixes (CYRINO et al., 2010).

O estado do Amapá possui notório potencial para o crescimento da piscicultura, principalmente por apresentar uma ampla variedade de espécies de peixes nativas com ótimas aceitação no mercado, clima propício e disponibilidade de recursos hídricos capaz de sustentar uma produção continuada (TAVARES-DIAS, 2011; OBA-YOSHIOKA et al., 2015).

Diante desse cenário, torna-se necessário a realização de novos estudos voltados as formas de uso dos recursos hídricos pela piscicultura no estado do Amapá e os impactos gerados pela atividade. Assim, o presente estudo teve como objetivo avaliar a qualidade da água e os efluentes oriundos do cultivo de peixes, através das medições das variáveis físico-químicas e biológica (clorofila-a), buscando caracterizar os possíveis impactos ambientais da atividade de piscicultura realizada no município de Macapá, no Estado do Amapá.

\section{MATERIAIS E MÉTODOS}

\section{Área de estudo}

O presente estudo foi realizado no município de Macapá, capital do estado do Amapá, na qual foram investigados dois viveiros escavados de empreendimentos de piscicultura distintas, no distrito de Fazendinha entre as coordenadas $0^{\circ} 2^{\prime} 32,36^{\prime \prime}$ Sul e $51^{\circ} 7^{\prime} 33,97^{\prime \prime}$ Oeste (Ponto I), e no bairro Zerão entre $0^{\circ} 0^{\prime} 35,97^{\prime \prime}$ Sul e $5^{\circ} 6^{\prime} 17,47^{\prime \prime}$ Oeste (Ponto II) respectivamente (Figura 1). 


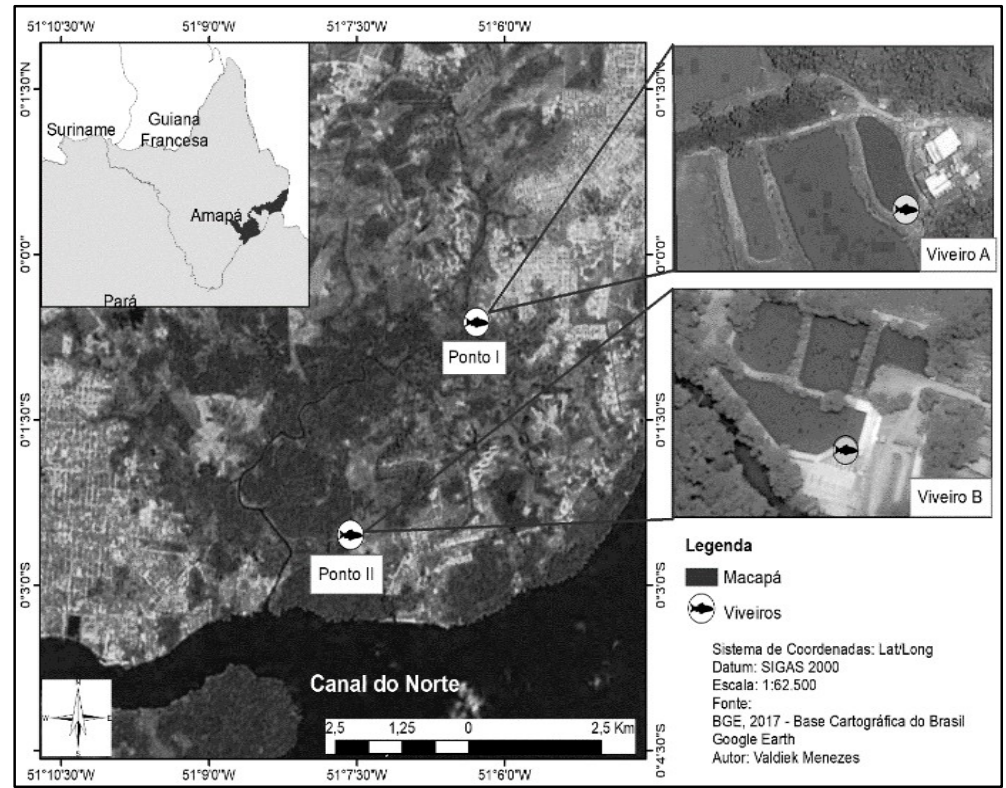

Figura 1: Localização dos viveiros (A e B) de piscicultura monitorados em Macapá, Amapá.

\section{Viveiro (A) - Ponto I}

O local em estudo trata-se de um viveiro escavado com fundo recoberto de argila em formato retangular, destinado à criação de alevinos, equivalente a $1.200 \mathrm{~m}^{2}$ (20 m largura x $60 \mathrm{~m}$ comprimento $\times 1.60$ $\mathrm{m}$ de profundidade). Na propriedade funcionam ao todo, 26 viveiros de cultivo, com produção totalmente destinada ao abastecimento do comércio local e a reposição do estoque de um viveiro pesque-pague da propriedade.

O sistema de cultivo empregado foi o semi-intensivo, com fornecimento de ração extrusada na alimentação dos peixes e troca total de água nos viveiros ao final do ciclo de produção. A água para o abastecimento dos viveiros é obtida de um igarapé, denominado de "igarapé da Fortaleza", e todo processo foi realizado por meio de bombeamento e gravidade.

O primeiro ciclo de cultivo ocorreu neste local no período de janeiro a março de 2012, com cerca de 2.000 exemplares de pós-larvas do híbrido tambacu, espécie obtida do cruzamento do Colossoma macropomum com o Piaractus mesopotamicus. O segundo ciclo ocorreu de março a junho de 2012, com póslarvas da espécie tambaqui Colossoma macropomum (quantidade de indivíduos não informada pelo piscicultor). Os animais receberam durante o período da pesquisa em sua alimentação o equivalente a 800 g/dia de ração comercial com $45 \%$ de PB (proteína bruta).

Após a transferência dos alevinos ao final do primeiro ciclo (mês de março), realizou-se a troca total de água deste viveiro, seguido do processo de calagem e adubação. Para a realização destes processos foram utilizados calcário dolomítico, adubo composto por nitrogênio, fósforo e potássio (NPK) e adubação orgânica (esterco animal) (quantidade utilizada neste processo não foi informada pelo piscicultor). Após o esvaziamento do viveiro, houve o reabastecimento total com auxílio de um motor bomba. Não se utilizou aeradores neste ponto durante a realização do estudo. 


\section{Viveiro (B) - Ponto II}

Trata-se de um viveiro escavado pesque-pague de formato retangular medindo $2000 \mathrm{~m}^{2}(40 \mathrm{~m}$ largura $\times 50$ m comprimento $\times 1.80$ m de profundidade). A propriedade possui cinco viveiros escavados, todos em pleno funcionamento com uma produção destinada exclusivamente a atividade de pesque-pague. Não foi informado a data do início do ciclo de cultivo, nem a quantidade de peixes presentes no viveiro. As espécies cultivadas foram o tambaqui Colossoma macropomum e a tilápia Oreochromis sp.

O sistema de cultivo empregado foi o extensivo, sem o fornecimento de ração para os animais com frequência; com a maior parte da alimentação dos peixes sendo obtida de forma natural, através do consumo de insumos presentes no ambiente (plâncton). Observou-se que este viveiro era interligado aos outros viveiros da piscicultura por meio de uma tubulação de policloreto de vinila (PVC). Assim como no viveiro anterior, a fonte de abastecimento deste empreendimento foi o 'igarapé da Fortaleza', onde todo processo foi realizado por bombeamento. Não houve troca total da água nos viveiros, apenas a reposição das perdas por evaporação e infiltração, nem utilizou- se aeradores ou equipamentos para a melhoria da qualidade da água.

\section{Coletas e análises das amostras de água}

As coletas e análises físico-químicas e biológicas (clorofila- $a$ ) de água foram realizadas mensalmente, de janeiro a julho no viveiro (A) e de janeiro a outubro para o viveiro (B) em 2012, sempre nos primeiros 30 cm da superfície da coluna d'água, entre 08:00 as 10:00 horas do dia.

As variáveis físico-químicas e biológicas analisadas foram: oxigênio dissolvido (mg/L), pH (0-14), condutividade elétrica $(\mu \mathrm{S} / \mathrm{cm})$, transparência $(\mathrm{cm})$, turbidez (NTU), cor aparente $(\mathrm{mg} / \mathrm{L}), \mathrm{clorofila}-a(\mu \mathrm{g} / \mathrm{L})$, cloretos $(\mathrm{mg} / \mathrm{L})$, sólidos totais dissolvidos $(\mathrm{mg} / \mathrm{L})$, ferro total $(\mathrm{mg} / \mathrm{L})$, dureza total $(\mathrm{mg} / \mathrm{L})$, temperatura do ar e da água $\left({ }^{\circ} \mathrm{C}\right)$.

As medições das variáveis foram realizadas com auxílio de oxímetro portátil (MO 880 Instrutemp), pHmetro de mesa (Q400 AS Quimis), condutivímetro (CD 4303 Lutron), termômetro de mercúrio (9775/03 Incoterm), tubidímetro (Q279P Quimis) e disco de Secchi.

As análises de clorofila- $a$, turbidez, cloretos, sólidos totais dissolvidos, ferro total, cor aparente e $\mathrm{pH}$ foram realizadas no Laboratório de Geoquímica de Águas e Sedimentos do Instituto de Pesquisas Cientificas e Tecnológicas do Estado do Amapá (DGAS/IEPA). Para as análises, foram coletadas amostras de água em garrafas de $500 \mathrm{ml}$ de polietileno, onde as mesmas foram acondicionadas em urnas térmicas com gelo e transportadas adequadamente ao respectivo laboratório para análises no mesmo dia.

Os resultados de clorofila-a foram obtidos pelo método de extração por acetona e leitura em espectrofotometria. Para as análises de clorofila- $a$ utilizou-se um sistema de filtração composto por copos, membrana de celulose (branca lisa, HÁ em ésteres de celulose 0,45 micra, $47 \mathrm{~mm}$ ), bomba a vácuo (VWR TM/vacum gás pump), centrifuga de tubos microprocessada (QUIMIS, Q222TM) e espectrofotômetro (nova instrumente 1800 UV). 
As medições de cloretos e dureza total nos viveiros foram realizadas somente até o mês de junho. Todos os procedimentos de coleta, preservação e análises foram realizados de acordo com os descritos Standard Methods for the Examination of Water and Waste Water (APHA, 1992).

\section{Análise dos dados}

Utilizou-se o programa Microsoft Excel e suas ferramentas para cálculos e projeções de gráficos, onde os resultados das análises foram organizados em planilhas eletrônicas para avaliação. Para a comparação das médias dos resultados das variáveis físico-químicas e biológica (clorofila- $a$ ) dos viveiros (A e B), aplicou-se o teste t de Student. A medição do grau de associação e comportamento dos resultados dos parâmetros físicoquímico e biológico dos viveiros ( $\mathrm{A}$ e B), foram obtidos através dos cálculos de correlações lineares entre duas variáveis.

Neste estudo foram consultados os dados de pluviosidade anual e insolação total do Instituto Nacional de Meteorologia (INMET) para o ano de 2012. Realizou- se a comparação das médias dos resultados do estudo com os valores estabelecidos pelas resoluções do CONAMA de $n^{\circ}$ 357/2005 e n 430/2011.

\section{RESULTADOS}

Na Tabela 1 estão descritos os resultados das médias dos parâmetros físico-químicos da água. Quando comparada as médias dos parâmetros obtidos nos viveiros ( $\mathrm{e}$ B) com os limites de qualidade de água das resoluções n 357/2005 e 430/2011 do Conselho Nacional do Meio Ambiente (CONAMA), notou-se que as médias dos parâmetros cor aparente e clorofila- $a$ dos viveiros não se adequaram a legislação vigente, estando acima dos limites recomendados pelas referidas resoluções.

Tabela 1: Apresentação das médias e desvio padrão dos parâmetros físico-químicos de qualidade da água dos viveiros (A e B) obtidos em 2012, assim como os valores estabelecidos pelas resoluções vigentes para classificação de águas doce de Classe (2) e efluentes do CONAMA.

\begin{tabular}{|l|l|l|l|l|}
\hline Parâmetros & Viveiro A & Viveiro B & CONAMA 357/2005 & CONAMA 430/2011 \\
\hline Oxigênio Dissolvido $(\mathrm{mg} / \mathrm{L})$ & $5,62 \pm 2,75$ & $8,33 \pm 0,96$ & $\geq 5 \mathrm{mg} / \mathrm{L}$ & - \\
\hline pH $(0-14)$ & $7,59 \pm 1,22$ & $8,38 \pm 0,74$ & 6 a 9 & 5 a 9 \\
\hline Condutividade Elétrica $(\mu \mathrm{S} / \mathrm{cm})$ & $76,79 \pm 10,56$ & $119,16 \pm 56,26$ & - & - \\
\hline Clorofila- $a(\mu \mathrm{g} / \mathrm{L})$ & $87,04 \pm 47,77$ & $126,36 \pm 67,42$ & $30 \mathrm{\mu g} / \mathrm{L}$ & - \\
\hline Transparência da água $(\mathrm{cm})$ & $33,33 \pm 12,52$ & $21,80 \pm 6,25$ & - & - \\
\hline Turbidez $(\mathrm{NTU})$ & $50,07 \pm 50,24$ & $91,11 \pm 30,90$ & $100 \mathrm{NTU}$ & - \\
\hline Cor Aparente $(\mathrm{mg} / \mathrm{L})$ & $269,60 \pm 128,84$ & $518,86 \pm 200,20$ & - & - \\
\hline Sólidos Totais Dissolvidos $(\mathrm{mg} / \mathrm{L})$ & $40,60 \pm 7,14$ & $58,89 \pm 27,41$ & $500 \mathrm{mg} / \mathrm{L}$ & - \\
\hline Dureza Total $(\mathrm{mg} / \mathrm{L})$ & $30,36 \pm 6,30$ & $21 \pm 5,48$ & $500 \mathrm{mg} / \mathrm{L}$ & - \\
\hline Cloretos $(\mathrm{mg} / \mathrm{L})$ & $8,30 \pm 1,52$ & $21 \pm 9,82$ & - & - \\
\hline Ferro Total $(\mathrm{mg} / \mathrm{L})$ & - & - & - & - \\
\hline Temperatura da água $\left({ }^{\circ} \mathrm{C}\right)$ & $29,05 \pm 0,81$ & $30,42 \pm 0,88$ & - & $<40{ }^{\circ} \mathrm{C}$ \\
\hline Temperatura do ar $\left({ }^{\circ} \mathrm{C}\right)$ & $29,67 \pm 2,09$ & $29,09 \pm 1,82$ & - & - \\
\hline
\end{tabular}

Com aplicação do teste t 'Student' $(p<0,05)$, constatou-se diferença entre as médias dos parâmetros de oxigênio dissolvido (OD), transparência, dureza total, cloretos e temperatura da água entre os viveiros. Não houve diferença significativa entre as médias dos demais parâmetros.

Não foram detectadas quantidades significativas de ferro total, possívelmente devido o método de 
detecção adotado neste estudo, onde o valor mínimo foi de $10^{-9} \mathrm{~g} / \mathrm{L}$, estando este valor abaixo de $3 \mathrm{mg} / \mathrm{L}$, o qual é determinado como limite de concentração pelo CONAMA no 357/2005.

Durante o período de estudo o valor médio de oxigênio dissolvido registrado no viveiro (A) foi de $5,62 \mathrm{mg} / \mathrm{L}$, com variação de 1,23 a 8,80 mg/L (Figura 2). O valor mínimo (1,23 mg/L) obtido no mês de janeiro esteve abaixo do que é recomendado pela legislação vigente CONAMA 357/2005 ( $\geq 5 \mathrm{mg} / \mathrm{L}$ ). No entato a média $(5,62 \mathrm{mg} / \mathrm{L})$ registrada esteve condizente com o padrão determinado pelo CONAMA.

Os motivos para o baixo valor de oxigênio dissolvido (OD) registrado no mês de janeiro no viveiro (A), pode estar relacionado aos horários de coletas e medições realizadas neste ponto que foram entre as 08:00 às 09:00 horas. No período de realização das coletas, pode-se observar uma grande quantidade de material em suspensão (detritos orgânicos e inorgânicos) na água de cultivo do viveiro (A) no mês de janeiro, o que pode ter contribuído para a diminuição da transparência da água $(20 \mathrm{~cm})$ e para elevação dos valores de turbidez (151 NTU) e cor aparente $(470 \mathrm{mg} / \mathrm{L})$ neste período.

O aumento da carga de sedimentos observado no mês de janeiro no viveiro (A) pode estar relacionado ao abastecimento realizado por bombeamento, visto que o início do ciclo de cultivo neste ponto iniciou a partir da segunda quinzena deste mês. O aumento de sedimentos dissolvidos e em suspensão observados neste ponto, causou a redução da zona eufótica neste período no viveiro (A), em razão da diminuição da penetração de luz solar na camada superficial da água do viveiro, sendo a zona de maior produtividade de oxigênio pela atividade fotossintética nesse ambiente.

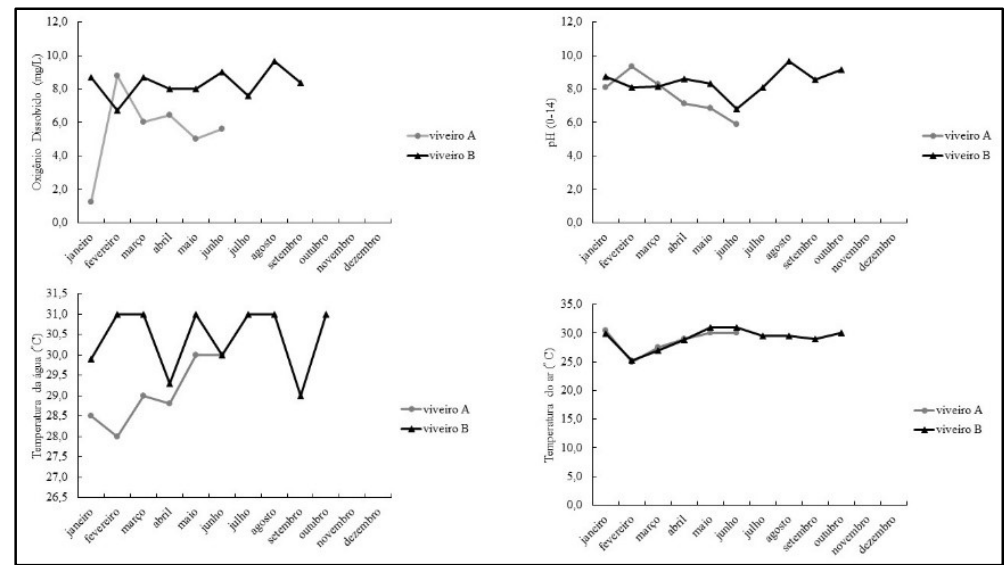

Figura 2: Parâmetros Oxigênio Dissolvido (OD), pH, Temperatura da água e ar analisados nos viveiros (A e B) em Macapá.

O consumo de oxigênio dissolvido (OD) no viveiro $(A)$ ocorrido em janeiro, pode também ter sido influenciado pelo aumento dos organismos planctônicos e pelo não uso de aeradores durante o período noturno, fazendo com que o consumo desse gás no período noturno fosse maior, devido as atividades desenvolvidas pelos organismos aquáticos (respiração) e as atividades oxidativas (decomposição da matéria orgânica).

Não houve variações elevadas de oxigênio dissolvido (OD) no viveiro (B) durante os meses de estudo, registrando valor mínimo de 6,73 mg/L e máximo de $9,97 \mathrm{mg} / \mathrm{L}$, estando o valor médio de 8,33 mg/L acima do limite recomendado pelo CONAMA ( $>5 \mathrm{mg} / \mathrm{L}$ ). No entanto, durante os meses de estudo, notou-se que as 
concentrações de oxigênio dissolvido no viveiro (B) foram maiores a partir do segundo semestre, alcançando valor máximo de 9,97 mg/L, sendo este o período de estiagem (seca) na região do estudo, período com maiores horas de insolação, o que pode ter favorecido a produção deste gás dentro do ambiente de cultivo por meio da atividade de fotossíntese.

A incidência solar total obtida no ano de 2012 (Figura 3), pode ter sido influência tambem sobre o comportamento do $\mathrm{pH}$ e de clorofila- $a$ no viveiro (B); onde os valores destes parâmetros foram maiores a partir do segundo semestre, período com maiores horas de insolação. Pode-se observar o crescimento do período de insolação total no decorrer dos meses do ano de 2012, registrando valor de insolação minímo de 126,9 horas (fevereiro) e a parti do segundo semestre, valor máximo de 294,8 horas de insolação (novembro), com média de 221,18 horas.

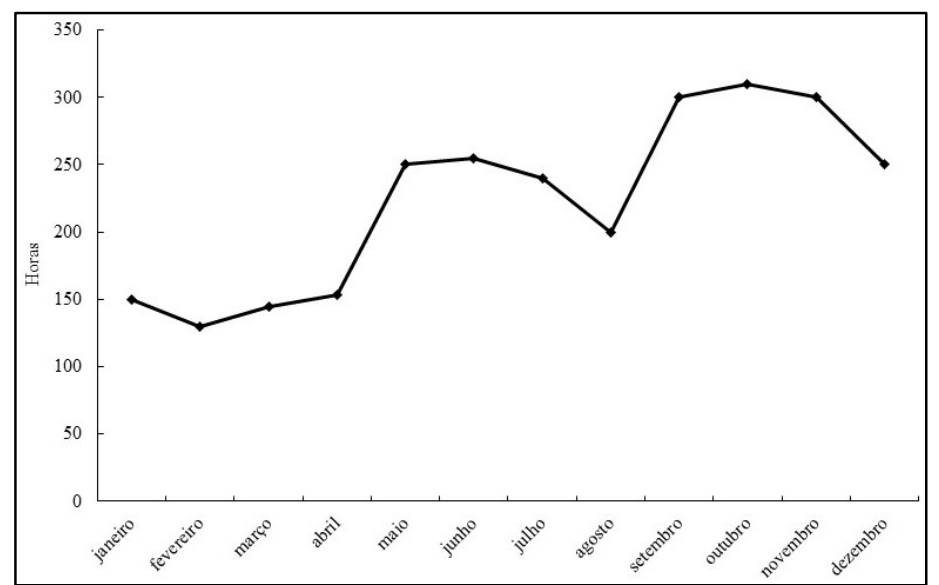

Figura 3: Insolação total do ano de 2012 registrada em Macapá-AP. Fonte: INMET (2013).

Os valores de pH da água dos viveiros ( $\mathrm{A} \mathrm{e} \mathrm{B)} \mathrm{(Figura} \mathrm{2)} \mathrm{mantiveram-se} \mathrm{ligeiramente} \mathrm{na} \mathrm{neutralidade}$ a alcalina, com valor médio de 7,59 (viveiro A) e 8,38 (viveiro B) (Tabela 1 e Figura 2), estando estes valores de acordo com os limites do CONAMA 357/2005 e 430/2011 (pH entre 6-9).

No viveiro (B) os valores observados de $\mathrm{pH}$ foram maiores a partir do segundo semestre, assim como os valores de oxigênio dissolvido já demonstrados anteriormente. A produtividade primária apresentada deste viveiro pode ter causado a elevação dos valores de $\mathrm{pH}$ neste ambiente de cultivo durante este período.

Durante os meses de março, abril, maio e junho, os viveiros (A e B) demonstraram semelhanças em relação ao comportamento dos valores de pH neste período, sofrendo diminuição destes, registrando no mês de junho os valores de $\mathrm{pH}$ mais baixos, com pH 5,89 (viveiro A) e pH 6,79 (viveiro B). As possíveis causas para redução dos valores de $\mathrm{pH}$ dos viveiros ( $\mathrm{A}$ e $\mathrm{B}$ ) neste período estão ligadas ao período chuvoso tido no primeiro semestre de 2012. Sendo que no viveiro (A) as diminuições dos valores de pH também podem ter tido influência da renovação da água utilizada no cultivo.

Durante o período de estudo, não houve variações elevadas em relação a temperatura do ar, com valores crescentes em relação aos meses do ano de 2012, estando na faixa entre 25 a $31{ }^{\circ} \mathrm{C}$ (Figura 2). Os valores de temperatura média registrada nos viveiros foram de $28,67^{\circ} \mathrm{C}$ (viveiro A) e de $29,01^{\circ} \mathrm{C}$ (viveiro B). Estando estes valores acima da média registrada pelo INMET no ano de 2012. Estes valores demonstram a 
estabilidade térmica da região de estudo, com ausências de variações bruscas. A temperatura da água de cultivo dos viveiros (A e B) (Figura 2) estiveram em crescimento em leve ocilações durante o período de estudo, com valores entre 28 a $31^{\circ} \mathrm{C}$, não ultrapassando o valor limite determinado pelo CONAMA 357/2005 $\left(<40^{\circ} \mathrm{C}\right)$.

A produtividade primária dos viveiros (A e B) pode ser demonstrada pela concentração de clorofila$a$, conforme a Figura 4 a seguir. Os valores de clorofila- $a$ do presente estudo estiveram acima do limite

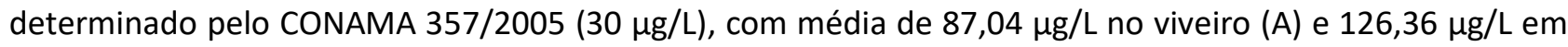
viveiro (B).

Houve o aumento dos valores de clorofila-a no viveiro (A) durante o primeiro semestre de 2012, nos meses de janeiro $(50,25 \mu \mathrm{g} / \mathrm{L})$, fevereiro $(100,10 \mu \mathrm{g} / \mathrm{L})$, março $(122,82 \mu \mathrm{g} / \mathrm{L})$ e abril $(168,39 \mu \mathrm{g} / \mathrm{L})$, sendo neste ultimo registrado o maior valor deste ponto. O aumento dos valores de clorofila- $a$ no mês de abril neste ponto, pode ter sido influenciado pela troca de água, adubação e calagem realizada neste mês.

No viveiro (B) as concentrações de clorofila- $a$ também estiveram em crescimento, chegando a atingir cerca de 194,38 $\mu \mathrm{g} / \mathrm{L}$ no mês de abril. Sendo que os maiores valores de clorofila-a registrados neste ponto foram obtidos nos meses de setembro $(215,26 \mu \mathrm{g} / \mathrm{L})$ e outubro $(229,62 \mu \mathrm{g} / \mathrm{L})$. Observou-se que as altas concentrações de clorofila- $a$ no viveiro (B), ocorreram principalmente a partir do segundo semestre, devido a redução do período chuvoso e o aumento do período de insolação, resultando no aumento da produção de oxigênio dissolvido (OD) pelas atividades fotossintéticas, seguido dos aumentos dos valores de $\mathrm{pH}$ e das populações de organismos pigmentados.

Em ambos os viveiros ( $\mathrm{A}$ e $\mathrm{B}$ ), notou-se que durantes os meses de estudo a água dos viveiros apresentava uma coloração bastante esverdeada, o que demonstra como esses ambientes possuem elevadas concentrações de organismos pigmentados (algas), que estão concentradas principalmente nas regiões superficiais da coluna d'água. Por estes organismos estarem concentrado na região superficial, as variações sofridas nestes, interfere diretamente no comportamento de outros parâmetros. Exemplos dessas interferências podem ser observadas nas alterações de parâmetros como a transparência da água de cultivo.

A transparência da água de cultivo dos ambos os viveiros ( $\mathrm{A}$ e B) se apresentou baixa durante o período de estudo, estando entre a faixa de 15 a $55 \mathrm{~cm}$ (Figura 4). Os baixos valores de transparência tidos principalmente no viveiro (B), são resultado da presença de uma maior concentração de material de origem orgânica na água de cultivo neste ponto, como folhas e galhos. Outro fator que pode ter favorecido a redução da transparência da água neste ponto, deve-se ao aumento da densidade planctônica e da ausência de troca de água, que associadas a redução do volume de chuvas (segundo semestre), pode ter levado a uma maior concentração de material em suspensão, diminuindo assim a penetração de luz solar na coluna d' água.

No viveiro $(A)$, pode-se observar o aumento dos valores de transparência da água de cultivo durante o período de estudo, possivelmente em razão da baixa concentração de material em suspensão, que aumentou a zona eufótica da coluna d’água, devido à pouca dispersão de radiação. O maior valor de transparência da água registrado no viveiro (A), foi obtido no mês de abril $(55 \mathrm{~cm})$, período em que ocorreu 
a renovação de água neste ponto, fator que pode ter contribuído para aumento dos valores deste parâmetro.

Além da transparência, a pluviosidade crescente apresentada no primeiro semestre de 2012 (Figura 5), pode ter exercido influência sobre o comportamento de outros parâmetros, como turbidez, cor aparente, condutividade elétrica (CE), sólidos totais dissolvidos (STD), cloretos e dureza total, conforme serão demonstrados a seguir.

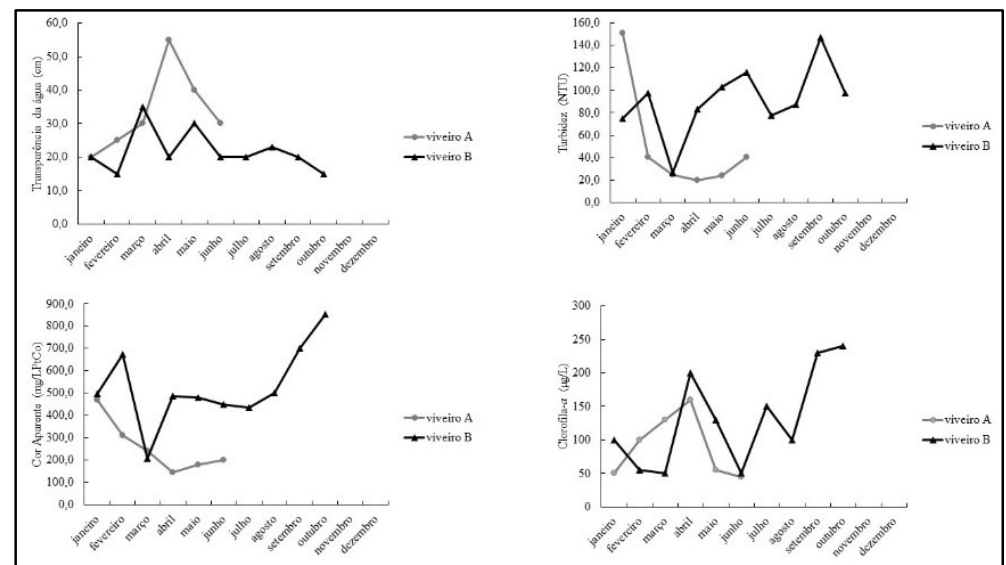

Figura 4: Parâmetros transparência da água, turbidez, cor aparente e clorofila- $a$ analisados nos viveiros (A e $B$ ) em Macapá-AP em 2012.

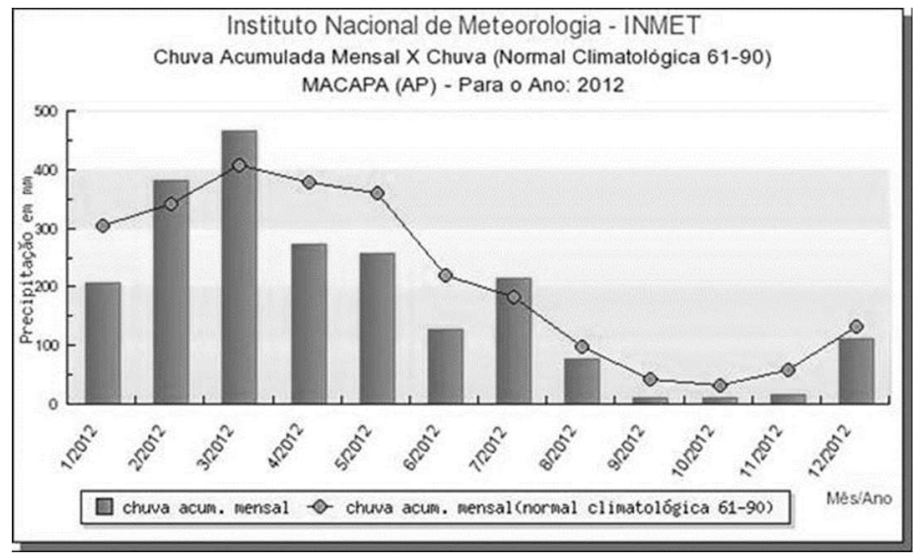

Figura 5: Níveis de variação de precipitação (mm) mensal de 2012 em Macapá, Amapá. Fonte: INMET (2013).

Segundo os dados do Instituto Nacional de Meteorologia (INMET), no primeiro semestre do ano de 2012, ocorre a elevação dos níveis de precipitação tida nos meses de janeiro, fevereiro e março, com redução destes níveis a partir do mês de julho.

Os valores de turbidez da água do viveiro (A) apresentaram variação em torno de 19,63 a 151 NTU (Figura 4). Sendo o maior valor de turbidez neste ponto registrado no mês de janeiro (151 NTU). Nota-se que a partir do mês de janeiro, houve uma redução dos valores de turbidez no viveiro (A) até o mês de abril, com crescimento dos valores nos meses seguintes de maio a junho. A redução dos valores de turbidez neste período, podem ter sofrido influência da alta pluviosidade registrada, conforme demonstram os dados de precipitação do Instituto Nacional de Meteorologia (INMET) (Figura 5).

Já a elevação observada da turbidez no viveiro $(A)$ em janeiro, pode ter ocorrido devido ao processo de abastecimento, que foi realizado por meio de bombeamento, feito alguns dias antes do início das medições físico-químicas, o que pode ter movimentado uma grande quantidade de partículas suspensas na 
água de cultivo como: argila, detritos orgânicos e inorgânicos.

Os valores de turbidez obtidos no viveiro (B), apresentaram crescimento principalmente a partir do segundo semestre de 2012, sendo este aumento coincidente com o período de redução das chuvas em Macapá conforme demonstrado anteriormente na Figura 4. Alguns fatores, como a ausência de reposição ou troca parcial de água utilizada no cultivo, também podem ter contribuído para aumento dos valores de turbidez neste ponto, resultando assim em uma maior concentração dos materiais suspensos.

Os viveiros demonstraram altos valores de cor aparente (Figura 4) com média 269,60 mg/L (viveiro A) e 518,86 mg/L (viveiro B), estando estes valores acima do que é determinado pela resolução 357/2005 do CONAMA (75 mg/L). Nota-se certa semelhança no comportamento dos valores de cor aparente com os de turbidez que foram demonstrados anteriormente. Os valores de cor aparente foram mais elevados no viveiro (B), a partir do segundo semestre de 2012, período que coincide com a redução do regime de chuvas na região.

Entre os fatores que podem ter contribuído para as modificações na coloração da água de cultivo durante os meses de estudo, estão a quantidade excessiva de substâncias húmicas dissolvidas, materiais em suspensão oriunda da degradação das sobras de ração, folhas, pedaços de madeira, excretas dos peixes, erosões do talude e aumento da massa planctônica.

As medições de condutividade elétrica (CE) nos viveiros (A e B) (Figura 6) não apresentaram oscilações significativas durante os meses de estudo, com médias de $76,79 \mu \mathrm{S} / \mathrm{cm}$ (viveiro A) e de 119,16 $\mu \mathrm{S} / \mathrm{cm}$ (viveiro B). No entanto, nota-se a redução desses valores nos pontos em estudo durante o primeiro semestre do ano, coincidindo com o período de chuvas mais intensas tidas neste período na região.

$O$ viveiro $(A)$ apresentou no mês de março seu maior valor registrado de condutividade elétrica (CE), que foi de $86,23 \mu \mathrm{S} / \mathrm{cm}$. Durante os meses de abril a maio, ocorreu uma redução dos valores de condutividade elétrica neste ponto, possivelmente este comportamento se deu devido ao regime chuvoso tido no primeiro semestre, principalmente no mês de março $(470 \mathrm{~mm})$, além da troca de água realizada no mês de abril, evento que pode ter influenciado na diminuição na concentração de íons dissolvidos neste ambiente de cultivo.

No viveiro (B), o mês de janeiro foi o de maior valor com $259 \mu \mathrm{S} / \mathrm{cm}$, tais valores demonstram os picos de maior concentração iônica nesses pontos. Este aumento em janeiro é resultado da grande quantidade de material dissolvido presente neste ambiente, tal fato é demonstrado também com elevação dos valores de turbidez, cor aparente e redução da transparência registrada neste mês.

Com a redução da pluviosidade a partir do segundo semestre, ocorre elevação dos valores de condutividade elétrica $(\mathrm{CE})$ no viveiro (B), em razão de uma maior concentração de íons dissolvidos na água de cultivo. As oscilações da condutividade elétrica registrada nos viveiros ( $A$ e $B$ ), foram semelhantes ao comportamento dos parâmetros sólidos totais dissolvidos (STD) e cloretos, conforme a Figura 6.

Os valores de sólidos totais dissolvidos (STD) apresentaram médias de 40,60 mg/L (viveiro A) e de $58,89 \mathrm{mg} / \mathrm{L}$ (viveiro B), estando estes valores abaixo do limite determinado pela resolução 357/2005 do 
CONAMA (500 mg/L). No viveiro (B) observa-se que ocorre a diminuição dos valores deste parâmetro a partir de janeiro (112,50 mg/L) até o mês de julho (32,40 mg/L). A elevação dos valores de sólidos totais dissolvidos (STD) no viveiro (B), contribuiu diretamente para o aumento dos valores de condutividade elétrica (CE) neste ponto.

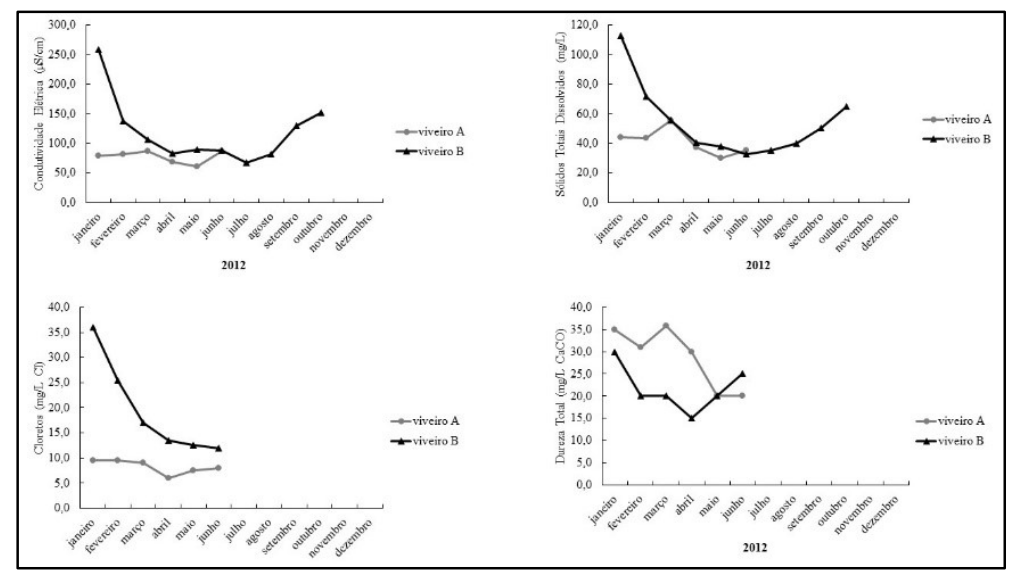

Figura 6: Parâmetros condutividade elétrica, sólidos totais dissolvidos, cloretos e dureza total analisados nos viveiros (A e B) em Macapá-AP em 2012.

Os valores mínimos de cloretos (Figura 6) detectados nas amostras de água dos viveiros (A e B), foram de $6 \mathrm{mg} / \mathrm{L}$ e máximo de 9,50 mg/L com média de $8,30 \mathrm{mg} / \mathrm{L}$ no viveiro (A) e de 12,5 mg/L a $36 \mathrm{mg} / \mathrm{L}$ com média de $21 \mathrm{mg} / \mathrm{L}$ no viveiro (B). Pode-se observar que a variação dos valores de cloretos detctados nos viveiros ( $A$ e $B)$, foram similares ao comportamentos de variação dos valores de sólidos totais dissolvidos (STD) e condutividade elétrica (CE) para esse mesmo período.

A redução dos valores de cloretos no viveiro (B), é resultado da redução dos minerais e dos íons de cloretos dissolvidos na água de cultivo, tal redução se deu principalmente devido as chuvas do primeiro semestre, que resultou na dispersão dos íons deste parâmetros, causando a queda dos valores de condutividade elétrica (CE).

Assim como a alta dos valores de sólidos totais dissolvidos (STD) no início de 2012, na qual foi seguida de redução dos valores, no viveiro (B) os valores de cloretos estiveram em queda de janeiro a junho, onde obteve seu menor valor $12,5 \mathrm{mg} / \mathrm{L}$. No viveiro $(\mathrm{A})$ esta redução dos valores de cloretos ocorreu de janeiro até o mês de abril (6 mg/L). Os valores de cloretos estiveram abaixo do limite determinado pela resolução $357 / 2005$ do CONAMA (250 mg/L).

As análises da água dos viveiros (A e B) não demonstraram altos valores de dureza total, ficando entre 20 a 35,80 mg/L com média 30,36 mg/L em viveiro (A) e com cerca de 15 a $30 \mathrm{mg} / \mathrm{L}$, com média de 21 mg/L no viveiro (B). O fornecimento de ração possivelmente pode ter influenciado para obtenção de valores maiores de dureza total no viveiro (A). As rações para peixes têm em sua composição a presença de cálcio, fósforo, magnésio e outros elementos químicos na base de sua composição.

O uso de adubos químicos na correção de acidez do solo e da água de cultivo, também pode ter contribuído para a elevação dos valores de dureza total no viveiro (A). Exemplo disto foi observado durante as análises e coletas neste ponto no mês de abril, onde ocorreu a troca de água total, seguido dos processos 
de calagem e adubação orgânica, que causou a elevação dos valores de dureza total (alcançando 35,80 mg/L).

No entanto nota-se que no viveiro (B), a ausência do fornecimento de ração e da aplicação de adubos químicos pode ter influenciado na diminuição dos valores de dureza total até o mês de abril.

\section{DISCUSSÃO}

A qualidade da água em sistemas artificiais de criação de peixes é influenciada pelas características físicas, químicas e biológicas da água de abastecimento, do tipo de espécie cultivada, do manejo empregado e da quantidade de ração fornecida na alimentação dos animais (MACEDO et al., 2010). No presente estudo se observou nos viveiros ( $A$ e B) diferenças siginificativas entre as médias dos parâmetros: oxigênio dissolvido $(\mathrm{OD})$, transparência da água, dureza total, cloretos e temperatura da água.

Quando comparado os resultados do estudo com os limites de qualidade de água das resoluções $n^{\circ}$ 357/2005 e 430/2011 do CONAMA, notou-se que os valores de clorofila-a estiveram cima dos limites recomendados pelas referidas resoluções do Conselho.

Não foram detectados nas amostras de água dos viveiros ( $A$ e B), valores significativos de ferro total. Um fator que pode ter contribuido para não detecção de ferro total nas análises de água dos viveiros, foi uma possivel associação deste parâmetro ao sedimento presente ao fundo dos viveiros. Segundo Esteves et al. (2011) os íons de ferro $\left(\mathrm{Fe}^{3+}\right.$ e $\left.\mathrm{Fe}^{2+}\right)$ presentes na água podem estar de forma reduzida devido a baixas concentrações de oxigênio e pH, assim como a provavel associação deste elemento a substâncias orgânicas ligadas ao sedimento de fundo dos ambientes aquáticos.

As variações de oxigênio dissolvido (OD) observadas nos viveiros ( $A$ e $B$ ) durantes o período de estudo, pode estar relacionada diretamente com os horários de coletas e medições dos parâmetros, as diferentes práticas de manejo empregadas e a sazonalidade regional.

Durante o mês de janeiro foi observado no viveiro (A) baixos valores de oxigênio dissolvido (OD) $(1,23$ $\mathrm{mg} / \mathrm{L}$ ). Segundo Kubitza (2003) baixas concentrações de oxigênio dissolvido no ambiente de cultivo prejudicam o crescimento dos peixes, causam a redução da eficiência alimentar, favorece a incidência de doenças e a mortalidade dos peixes. Durante o cultivo de peixes as concentrações de oxigênio dissolvido devem ser mantidas acima de $5 \mathrm{mg} / \mathrm{L}$, faixa ideal para o desenvolvimento e sobrevivência dos animais (OSTRENSKY et al., 1998).

Baixas concentrações de oxigênio dissolvido também foram observadas por Azevedo et al. (2008) (4,5 mg/L), Oba-Yoshioka et al. (2015) (4,0 mg/L) e Barroncas et al. (2015) (2 mg/L) em análise das variáveis físico-químico da água em viveiros escavados utilizados no cultivo de tambaqui Colossoma macropomum e tambatinga (Colossoma macropomum x Piaractus brachypomus) em Macapá e no Amazonas. Os principais motivos apontados pelos autores para as reduções de oxigênio dissolvido foi o excesso de ração utilizada na alimentação dos peixes, a demora na renovação da água de cultivo, falta de aeração da água durante o período noturno, respiração dos organismos e pela fotossíntese.

Os valores da média de pH encontrados nas análises de água dos viveiros ( $\mathrm{A}$ e B) neste estudos são 
considerados como 'base', com 7,59 em viveiro (A) e 8,38 para o viveiro (B). Estes valores são caracteristicos de ambientes que apresentam elevada produtividade primária e altas taxas fotossintéticas, que resulta muitas vezes em uma maior remoção de $\mathrm{CO}_{2}$ dos ambientes de cultivo durante o período diurno (KUBITZA, 2003).

O valores de $\mathrm{pH}$ encontrados nos viveiros ( $\mathrm{A}$ e B), estão dentro de uma faixa de conforto aceitável na piscicultura (6,5 a 9,0) (OSTRENSKY et al., 1998; KUBITZA, 2003). Segundo Aride et al. (2007), espécies como o tambaqui quando expostos a situação de estresse excessivo em ambientes ácidos, acabam apresentando complicações principalmente nas funções de osmorregulação. Isto ocorre porque o pH atua sobre os processos de permeabilidade da membrana celular, interferindo diretamente no transporte iônico extra e intracelular dos organismos aquáticos e o ambiente (ESTEVES et al., 2011).

Durante o período de estudo, a variação da temperatura ambiente (ar) esteve em uma faixa de 25 a $31{ }^{\circ} \mathrm{C}$, com crescimento gradativo dos valores em decorrer do passar dos meses de 2012. Os valores mais elevados de temperatura ambiente foram registrados a partir do segundo semestre, no entanto não houve variações brusca desse parâmetro, o que demonstra a estabilidade térmica da região.

Mesmo sem alterações elevadas na temperatura ambiente, observou-se que a sazonalidade (níveis de precipitação e insolação) anual da região teve certa influência sobre o comportamentos de alguns parâmetros, como: oxigênio dissolvido (OD), pH, clorofila- $a$, transparência da água e condutividade elétrica. A influência da sazonalidade local tida sobre o comportamento dos parãmetros físico-quimico da água em viveiros de piscicultura também foram observados em estudos realizados na Amazônia (AZEVEDO et al., 2008; FREITAS et al., 2014) e em outras regiões do país (SIPAÚBA-TAVARES et al., 2007).

A influência da sazonalidade (insolação e precipitação) sobre o comportamento dos parâmetros físico-químicos também foram descritos por Freitas et al. (2014) em seus estudo sobre qualidade da água em viveiros escavados na criação de tambaqui no Amazonas, onde no período mais chuvoso (mês de maio) para sua região, houve redução dos valores de oxigênio dissolvido e temperatura da água dos viveiros, e no período mais seco (agosto, setembro e outubro) ocorreu redução da transparência da água e o aumentos dos valores de turbidez, $\mathrm{pH}$, dureza total, sólidos totais dissolvidos (STD), condutividade elétrica (CE) e temperatura da água. Comportamento este, semelhante aos que foram observados durante o período deste estudo.

Os valores médios de temperatura da água observados nos viveiros, 29,05 (A) e 30,42 (B) ${ }^{\circ} \mathrm{C}$ durante o período de estudo, estiveram dentro de uma faixa aceitavel para o cultivo de espécies de peixes tropicais (26 a $30^{\circ} \mathrm{C}$ ) (KUBITZA, 2003). O aumento dos valores de temperatura da água dos viveiros pode ter tido influência dos horários das coletas e medições e das condições climáticas locais, no momento da leitura dos dados do parâmetro. Variações de temperatura em águas superficiais nos viveiros de piscicultura, podem ocorrer em função do volume de água, da hora do dia e da época do ano (verão e inverno) da realização das medições (KUBITZA, 1998).

As práticas de manejo tiveram influência em relação ao comportamento de alguns parâmetros do 
viveiro (A) durante os meses de estudo, exemplo do aumento da transparência, clorofila- $a$, registrada no mês de abril neste ponto, após a renovação de água. Além da redução dos valores de turbidez, condutividade elétrica (CE), cor aparente, sólidos totais dissolvidos (STD), cloretos e dureza total. Segundo Kubitza (2003) a troca de água em ambientes de cultivo permite controlar a densidade do fitoplâncton e diluir a concentração dos resíduos orgânicos, dos metabolitos tóxicos (amônia, gás carbônico, nitrito, gás sulfídrico e o metano, entre outros) e dos nutrientes (nitrogênio e fósforo), retardando assim a deterioração da qualidade da água ao longo do cultivo.

Influência das práticas de manejo na qualidade da água em sistemas artificiais de cultivo foram descritos também por Sipaúba-Tavares et al. (2013), onde estas práticas são responsáveis pela introdução de nutrientes nesses ambientes, por meio de alimentos não consumidos, adubação e calagem, metabolitos e fezes de peixes. Os valores médios de transparência da água de 33,33 e 21,80 cm registrados nos viveiros (A e B) respectivamente, são indicativo de um ambiente com uma grande quantidade de nutrientes dissolvido, favorecendo assim a floração de algas e o aumento das comunidades planctônicas, podendo apresentar riscos ao cultivo, devido surgimento de diversos problemas, entre eles, a redução do oxigênio dissolvido no ambiente (KUBITZA, 2003). Fato este observado no mês de janeiro no viveiro (A), onde se registrou baixos valores de oxigênio dissolvido $(1,23 \mathrm{mg} / \mathrm{L})$, com uma transparência de $20 \mathrm{~cm}$.

Redução dos valores de oxigênio dissolvido associados a baixos valores de transparência da água em viveiros de piscicultura também foram observados por Barroncas et al. (2015) com valores médios de 50 a $53 \mathrm{~cm}$ de transparência com $2 \mathrm{mg} / \mathrm{L}$ de oxigênio dissolvido; Freitas et al. (2014) com valor médio de $50 \mathrm{~cm}$ de transparência e 4,5 mg/L de oxigênio dissolvido e por Azevedo et al. (2008) com valor médio de $20 \mathrm{~cm}$ e $4,7 \mathrm{mg} / \mathrm{L}$ de oxigênio dissolvido.

Os valores elevados na concentração de clorofila- $a$ obtidos nos viveiros (A) $(87,04 \mu \mathrm{g} / \mathrm{L})$ e viveiro (B) (126,36 $\mu \mathrm{g} / \mathrm{L}$ ), estão relacionados à grande massa de organismos pigmentados (algas) e das altas taxas fotossintética tidas nos ambientes de cultivo, como foram demonstrados anteriormente pelos resultados de $\mathrm{OD}, \mathrm{pH}$ e transparência da água.

Além destes, os níveis de insolação tidas nos meses de estudo e a concentração de nutrientes dos ambientes de cultivo, também pode ter tido influência sobre os valores de clorofila- $a$. Altos valores de clorofila- $a$ em viveiros escavados com sistema semi-intensivo também foram descritos por Sipaúba-Tavares

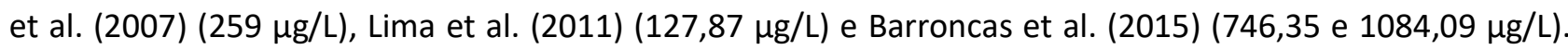
Segundo os autores as elevações dos valores deste parâmetro foram causadas pela adição de ração comercial, abastecimento e mineralização de adubo orgânico nos viveiros.

Os altos valores de turbidez registrados no mês de janeiro no viveiro (A) (151 NTU) e em setembro no viveiro (B) (147 NTU), podem ter sofrido influência do abastecimento realizado por bombeamento dias antes do início do cultivo dos peixes, que pode ter movimentado uma grande quantidade de partículas suspensas (argila, detritos orgânicos e inorgânicos) na água (caso do viveiro A), assim como da redução das chuvas a partir do segundo semestre e da ausência da reposição ou troca total da água de cultivo (caso do 
viveiro B) .

A medição da condutividade elétrica (CE) demonstrou as concentrações de íons presentes na água dos viveiros ( $A$ e B), onde os valores das médias foram de $76,79 \mu \mathrm{S} / \mathrm{cm}$ no viveiro (A) e de 119,16 $\mu \mathrm{S} / \mathrm{cm}$ no viveiro (B). Nota-se que o valor deste parâmetro em ambos viveiros teve redução durante o primeiro semestre de 2012. As causas das reduções dos valores deste parâmetro podem estar relacionadas ao período de chuvas mais intensa na região tida no primeiro semestre do respectivo ano (janeiro a maio).

Reduções dos valores dos parâmetros sólidos totais dissolvidos (STD), cloretos, dureza total e cor aparente também ocorreram de forma mais intensa no primeiro semestre de 2012, visto que estes parâmetros estão ligados de certa forma a quantidade de substâncias presentes na água e o grau de dissolução dessas substâncias pode ser medido pela condutividade elétrica (CE) da água, demonstrando assim a redução na concentração de íons presentes nesses ambientes neste período.

No presente estudo os valores médios de dureza total estiveram dentro favoráveis ao cultivo de peixes de água doce (75 mg/L) (SILVA et al., 2013), com média de $30,36 \mathrm{mg} / \mathrm{L}$ no viveiro (A) e de $21 \mathrm{mg} / \mathrm{L}$ para o viveiro (B). Segundo Esteves et al. (2011), valores de dureza acima de 20 mg/L indicam águas de adquado poder tampão, onde as flutuações de pH são menos acentuadas.

No entanto os valores de dureza total obtidos no viveiro (A) foram maiores que no viveiro (B). Possivelmente isto é resultado do fornecimento de ração e de adubos químicos, utilizados na correção da acides e adubação neste ponto, materiais que possuem em suas composições a presença de cálcio e magnésio, além de outros elementos químicos que podem influenciar no comportamento deste parâmetro.

Os valores dos parâmetros tidos em (B) demonstraram médias maiores dos que as do viveiro (A), fatores como a falta de troca de água e de aeração influenciou para o aumento desses parâmetros. A interligação observada do viveiro (B) com os outros viveiros da piscicultura, também pode ter tido influência direta sobre as variações dos parâmetros físicos, químicos e biológico registrados neste ponto.

\section{CONCLUSÕES}

Os altos nível de fertilização da água dos viveiros, traz a preocupação em relação ao despejo destes e os seus efeitos aos ambientes receptores adjacentes, tornando necessário mais estudos técnicos e científicos para aumento da produção, desenvolvimento de novas práticas e técnicas de cultivo, além de garantir a sustentabilidade ambiental, não colocando em risco os recursos hídricos locais.

\section{REFERÊNCIAS}

ANJOS, M. R.; SOUZA, V. C.; SANTIAGO, R. C.; MACHADO, N. G.; BIUDES, M. S.; FULAN, J. A.. Piscicultura no sudoeste da Amazônia brasileira: o caso de Rondônia em 2009. Global Science and Technology, v.8, p.143-152, 2015.

AZEVEDO, R. C. J.; TAKIYAMA, L. R.. Caracterização físicoquímica da água em tanques de piscicultura, Município de Macapá-AP. Revista de Pesquisa e Iniciação Cientifica do Amapá, v.1, p.11-14, 2008.
ARIDE, P. H. R.; ROUBACH, R.; VAL, A. L.. Tolerance response of tambaqui Colossoma macropomun (Cuvier) to water $\mathrm{pH}$. Aquaculture Research, v.38, p.588-594, 2007.

BARRONCAS, M. F.; PEREIRA-FILHO, M.; GOMES, L. C.; ROUBACH, R.; ONO, E. A.. Efeitos da troca de água sobre os índices zootécnicos e qualidade dos efluentes na criação intensiva do tambaqui (Colossoma macropomum) em viveiros escavados. Revista Brasileira de Engenharia de Pesca, v.8, p.49-71, 2015. 
CYRINO, J. E. P.; BICUDO, A. J. A.; SADO, R. Y.; BORGHESI, R.; DAIRIKI, J. K.. A piscicultura e o ambiente: o uso de alimentos ambientalmente corretos em piscicultura. Revista Brasileira de Zootecnia, v.39, p.68-87, 2010.

ESTEVES, F. A.; MARINHO, C. C.. Carbono Inorgânico. In: ESTEVES, F. A.. Fundamentos de Limnologia. 3 ed. Rio de Janeiro: Interciência, 2011. p.209-238.

FREITAS, R. S.; BOIJINK, C. L.; MUNIZ, A. W.; DAIRIKI, J. K.; INOUE, L. A. K. A.. Qualidade da água e perspectiva para o gerenciamento ambiental dos cultivos de tambaqui no município de Rio Preto da Eva, AM. Scientia Amazônia, v.3, p.116-126, 2014.

IBGE. Instituto Brasileiro de Geografia e Estatística. A produção Aquícola Nacional de 2016. Dados de Pesquisa Agropecuária Municipal. Rio de Janeiro: IBGE, 2017.

INMET. Instituto Nacional de Meteorologia. Normais climatológicas do Brasil: precipitação acumulada mensal e anual (mm) e insolação total (horas). 2013.

KUBITZA, F.. Qualidade da água no cultivo de peixes e camarões. Jundiaí, 2003.

KUBITZA, F.. Qualidade da água na produção de peixes Parte I. Revista Panorama da Aquicultura, v.8, p.36-41, 1998.

MACEDO, C. F.; SIPAÚBA-TAVARES, L. H.. Eutrofização e qualidade da água na piscicultura: consequências e recomendações. Boletim do Instituto de Pesca de São Paulo, v.36, p.149-163, 2010.
FAO. Organización de Las Naciones Unidas Para La Alimentación y La Agricultura. El estado mundial de la pesca y la acuicultura: Contribuición a la seguridade alimentaria y la nutrición para todos. Roma: FAO, 2016.

OBA-YOSHIOKA, E. T.; ALMEIDA, R. S.; GEMAQUE, S. R. F.; BRASILIENSE, A. R. P.; SILVA, R. S.; MARINHO, R. G. B.. Substituição parcial da ração comercial por soja e milho cozidos e sua influência sobre o cultivo de híbridos tambatingas. Revista Biota Amazônia, v.5, p.61-67, 2015.

OSTRENSKY, A.; BOEGER, W.. Piscicultura: fundamentos e técnicas de manejo. Guaíba: Agropecuária LTDA, 1998.

CONAMA. Conselho Nacional do Meio Ambiente. Resolução no 430, de 13 de maio de 2011. CONAMA, 2015.

SILVA, A. D. R.; SANTOS, R. B.; BRUNO, A. M. S. S.; SOARES, E. C.. Cultivo de tambaqui em canais de abastecimento sob diferentes densidades de peixes. Revista Acta Amazônica, v.43, p.517-524, 2013.

SIPAÚBA-TAVARES, L. H.; MILLAN, R. N.; AMARAL, A. A.. Influence of management on the water quality and sediment in tropical fish farm. Journal of Water Resource and Protection, v.5, p.495-501, 2013.

SIPAÚBA-TAVARES, L. H.; GUARIGLIA, C. S. T.; BRAGA, F. M. $S$.. Effects of rainfall on water quality in six sequentially disposed fishponds with continuous water flow. Brazilian Journal of Biology, v.67, p.643-649, 2007.

TAVARES-DIAS, M.. Piscicultura continental no Estado do Amapá: Diagnostico e perspectiva. Boletim de Pesquisa e Desenvolvimento. Macapá: Embrapa Amapá, 2011.

A CBPC - Companhia Brasileira de Produção Científica (CNPJ: 11.221.422/0001-03) detém os direitos materiais desta publicação. Os direitos referem-se à publicação do trabalho em qualquer parte do mundo, incluindo os direitos às renovações, expansões e disseminações da contribuição, bem como outros direitos subsidiários. Todos os trabalhos publicados eletronicamente poderão posteriormente ser publicados em coletâneas impressas sob coordenação da Sustenere Publishing, da Companhia Brasileira de Produção Científica e seus parceiros autorizados. Os (as) autores (as) preservam os direitos autorais, mas não têm permissão para a publicação da contribuição em outro meio, impresso ou digital, em português ou em tradução. 